\title{
Is the detection of anti-Rhipicephalus sanguineus (Rs24p) antibodies a valuable epidemiological tool of tick infestation in dogs?
}

\author{
Hisashi INOKUMA*, Koichi OHNO, Takafumi ONISHI \\ Faculty of Agriculture, Yamaguchi University, 1677-1 Yoshida, Yamaguchi 753-8515, Japan
}

(Received 8 November 1999; accepted 11 February 2000)

\begin{abstract}
Antibodies against the $24 \mathrm{kDa}$ Rhipicephalus sanguineus (Rs24p) protein were detected by ELISA to evaluate the relationship between antibodies and tick infestation. The mean titer of 3 dogs that underwent 2 experimental infestations with adult ticks was transiently increased after the second infestation. There was a significant difference in mean titers between positive control dogs naturally infested with ticks and tick-naive dogs. These results suggested that anti-Rs $24 p$ antibodies detected by ELISA are a marker of tick exposure. There was no significant difference in mean titers between tick-naive dogs and seropositive dogs to Ehrlichia canis. Some dogs positive for $E$. canis antibodies showed, however, higher titers than most ticknaive dogs. $R$. sanguineus may be related to the E. canis infection in Japan.
\end{abstract}

anti-tick antibody / Ehrlichia canis / Rhipicephalus sanguineus

Résumé - La détection des anticorps anti-Rhipicephalus sanguineus (Rs24p) est-elle un outil épidémiologique valable d'infestation par les tiques chez les chiens ? Des anticorps contre une protéine de $24 \mathrm{kDa}$ de Rhipicephalus sanguineus (Rs24p) ont été détectés par ELISA pour évaluer le rapport entre l'anticorps et l'infestation par les tiques. Le titre moyen d'anticorps Rs $24 p$ chez les chiens qui ont à 2 reprises subi une infestation expérimentale avec des tiques adultes s'est élevé transitoirement dès la deuxième infestation. Une différence significative des titres moyens d'anticorps a été notée entre les chiens naturellement infestés par les tiques et les chiens naïfs. Ces résultats suggèrent que les anticorps anti-Rs24p détectés par ELISA sont le témoin d'une exposition répétée aux tiques. Aucune différence significative des titres moyens entre les chiens non infestés par les tiques et les chiens séropositifs vis-à-vis de Ehrlichia canis n'a été notée. Cependant, quelques chiens atteints d'ehrlichiose canine ont montré des titres plus élevés que la plupart des chiens naïfs, suggérant que $R$. sanguineus pourrait être associé à l'infection par E. canis au Japon.

anticorps anti-tique / Ehrlichia canis / Rhipicephalus sanguineus

* Correspondence and reprints

Temporary address until 30 september 2000, Unité des Rickettsies, Faculté de Médecine, 27 bd Jean Moulin, 13385 Marseille, France

Fax: (33) 4918303 90; e-mail: InokumaHisashi@ aol.com 


\section{INTRODUCTION}

Rhipicephalus sanguineus, a well-known vector of Ehrlichia canis [1], is not common in Japan except in tropical Okinawa [13]. Recently, dogs positive for antiE. canis antibodies were reported in the western part of Japan [6, 14]. Seropositivity to E. canis in dogs in the Yamaguchi Prefecture was $4.7 \%$ [6]. However, no evidence of $R$. sanguineus has been reported. The epidemiology for E. canis in mainland Japan remains unclear. The reason why some dogs are positive for E. canis without $R$. sanguineus is unknown.

The detection of anti-tick antibodies has been used as a biological marker of exposure to Ixodes dammini in humans [10-12]. Antibodies against a $24 \mathrm{kDa}$ protein derived from larvae of $R$. sanguineus (Rs24p) were also specifically produced in dogs after repeated infestation with adult ticks in our previous study [5]. Rs 24p is a protein that is considered to be related to saliva or the salivary gland of the tick [5]. In this study, we looked for anti-Rs $24 \mathrm{p}$ antibodies in canine sera using ELISA to evaluate the antibody level for an epidemiological study on tick infestation in dogs.

\section{MATERIALS AND METHODS}

\subsection{Canine sera}

\subsubsection{Experimental infestation}

For the experimental infestation, 3 ticknaive adult male Beagle dogs were used. Unfed female and male $R$. sanguineus were obtained from a colony maintained at our laboratory using rabbits (Japanese white, Kyudo, Japan). The ear bag method was used for tick infestation. The dogs were first infested with 10 pairs of adult $R$. sanguineus in ear bags on day 0 . This first infestation lasted until day 7 or 8 , when all engorged female ticks had dropped. On day 60 , each dog was infested a second time with 10 pairs of adults in ear bags. This infestation lasted for 7 to 9 days. Sera were obtained from each dog on days $0,6,12,18,24$ and 30 of the first infestation, and on days $0,6,12$, $18,24,30$ and 50 of the second infestation.

\subsubsection{Natural infestation}

Sera from 57 dogs naturally infested with $R$. sanguineus in Okinawa were used as positive controls (Rs+). These dogs were freeroaming and were captured on Okinawa Island during May 1997. Various degrees of infestation with $R$. sanguineus were confirmed by physical examination at the time of bleeding [4]. Negative control sera for tick infestation (Rs-) were obtained from 30 dogs kept in the Yamaguchi University. These dogs had never been infested with any ticks before the experiment.

For the antibody positive samples against E. canis (Ec), the sera of dogs collected between April 1994 and July 1998 were stored at $-20{ }^{\circ} \mathrm{C}$ at the Animal Hospital in Yamaguchi University. The dogs were from Yamaguchi and neighboring sites. The history of tick infestation was not recorded. Antibody titers against E. canis were measured by the indirect immunofluorescence technique [8]. Twenty-two dogs among 448 (4.9\%) were found to be positive for E. canis. These $22 \mathrm{dogs}$ did not show any clinical signs of ehrlichiasis such as fever, anemia or bleeding.

\subsection{Tick antigen for ELISA}

Unfed larvae were homogenized with ground glass homogenizers in $2.0 \mathrm{~mL}$ of phosphate buffered saline (PBS, $\mathrm{pH}$ 7.2) and $5 \mathrm{mM}$ phenylmethylsulfonyl fluoride (PMSF, Nakalai Tesque, Japan) in an ice bath. This crude extract was centrifuged at $7267 \times g$ for $10 \mathrm{~min}$ at $4{ }^{\circ} \mathrm{C}$. The supernatant was used as the source of further Rs $24 p$ purification. The extracts were separated by $12 \%$ SDS-PAGE under reducing conditions and then stained with Commassie blue. The 
band observed around $24 \mathrm{kDa}$ was cut from the gel and the protein was eluted with an electro-eluter (Model 422, Bio-Rad, USA). Then, the eluted protein was transferred to the nitrocellulose membranes by electrotransfer to examine the reactivity of Rs $24 p$ with the antibodies. The transferred proteins were stained with dog serum on day 12 of the second infestation, followed by a secondary antibody, alkaline phosphatase-conjugated anti-dog IgG (American Qualex, USA) and developed with an alkaline phosphatase conjugate substrate kit (Bio-Rad, USA). A single band was observed in the reaction of the eluted protein with serum from dogs infested twice with adult ticks. The eluted proteins were used as an antigen of Rs $24 p$ for ELISA.

\subsection{ELISA}

To detect the Rs $24 p$ antibodies in dogs by ELISA, U-bottom microtiter plates (96 wells, Greiner, Germany) were incubated overnight at $4{ }^{\circ} \mathrm{C}$ with separated Rs 24p (1 $\mu \mathrm{g} \cdot \mathrm{mL}^{-1}, 100 \mu \mathrm{L}$ per well) in $0.05 \mathrm{M}$ carbonate buffer ( $\mathrm{pH}$ 8.6) for the first step. Plates were rinsed twice with phosphate buffered saline, pH 7.2 (PBS) containing $0.05 \%$ Tween 20 (PBS Tween) and blocked with $1 \%$ gelatin in PBS for $1 \mathrm{~h}$ at $37^{\circ} \mathrm{C}$. The plates were then rinsed 3 times with PBS-Tween. Serum diluted 1:100 in PBS-Tween containing 1\% gelatin was added to each well $(100 \mu \mathrm{L})$ and incubated for $1 \mathrm{~h}$ at $37^{\circ} \mathrm{C}$. The plates were then rinsed 3 times with PBS-Tween, and $100 \mu \mathrm{L}$ horseradish peroxidase conjugated sheep anti-dog IgG (1:1000 in PBS-Tween, Cappel, USA) was added to each well. The plates were incubated for $1 \mathrm{~h}$ at $37^{\circ} \mathrm{C}$ and then rinsed 3 times with PBS-Tween. After addition of $100 \mu \mathrm{L}$ of ABTS peroxidase substrate (Kirkegard \& Perry Laboratories, USA) to each well, the plates were incubated for $15 \mathrm{~min}$ at $37^{\circ} \mathrm{C}$. The optical density (OD) in each well was read on an ELISA reader (Multiscan Bichromatic, Lab- systems, USA) at a wavelength of $405 \mathrm{~nm}$. Simultaneously, a control by ELISA with no antigen was used to evaluate non-specific reactions. The cut off value was the mean $+2 \times$ (standard deviation) of the negative control dogs.

\subsection{Statistics}

The data of both experimental and natural infestations were analyzed statistically by using Kruskal-Wallis ANOVA in a statistical package of StatView 4.5J (Hulinks, Japan). Non-parametric Bonferroni-type multiple comparison analysis was used as a post-hoc test of the data. The significant level of these statistical analyses was defined as $p<0.05$.

\section{RESULTS}

The changes of mean titers in 3 dogs experimentally infested with adult $R$. sanguineus are shown in Table I. The mean titer showed an increase by day 6 of the second infestation which continued until day 18 and decreased on day 24 of the second infestation. These changes were not statistically significant.

The mean \pm standard deviation of the titers in groups Rs- and Rs+ were $0.210 \pm$ 0.117 and $0.439 \pm 0.219$, respectively (Fig. 1). The ELISA cut off value was calculated as 0.444 . When comparing the mean titer of positive control dogs naturally infested with ticks in Okinawa and tick naive dogs, a significant difference $(p<0.05)$ was observed. However, the titer of many individuals in the positive control showed a lower level compared with the mean of the negative control. The mean \pm standard deviation of the titer in group Ec was $0.298 \pm$ 0.197 , but the difference in the mean titer between groups Ec and Rs- was not significant. Six of 22 E. canis seropositive dogs showed titers higher than cut off value. 
Table I. The titers of anti-Rs24p antibodies (OD at $405 \mathrm{~nm}$ ) in 3 dogs infested twice with adult Rhipicephalus sanguineus.

\begin{tabular}{|c|c|c|c|c|c|c|c|c|c|c|c|c|c|}
\hline \multirow[b]{2}{*}{ Dog } & \multicolumn{6}{|c|}{ Days after the first infestation } & \multicolumn{7}{|c|}{ Days after the second infestation ${ }^{a}$} \\
\hline & 0 & 6 & 1 & 8 & 24 & 30 & 0 & 6 & 12 & 18 & 24 & 30 & 50 \\
\hline No & & & & & & & & & & & & & \\
\hline No.2 & 0. & 7 & 0.1 & 0. & & & & 0.3 & & 0.332 & 0.128 & 0.155 & 0. \\
\hline No. & 0. & 0.274 & & 0. & & & & & & 0.5 & 0.225 & 0.311 & 0.236 \\
\hline $\mathrm{Me}$ & & 0.228 & & & & & & 0.344 & & 0.366 & & 0.174 & 0.1 \\
\hline $\mathrm{SD}^{\mathrm{b}}$ & 0.035 & 0.051 & 0.080 & 0.053 & 0.008 & 0.077 & 0.170 & 0.155 & 0.043 & 0.213 & 0.058 & 0.115 & 0.071 \\
\hline
\end{tabular}

a Day 0 of the second infestation is day 60 after the first infestation; ${ }^{\text {b }}$ SD: standard deviation.

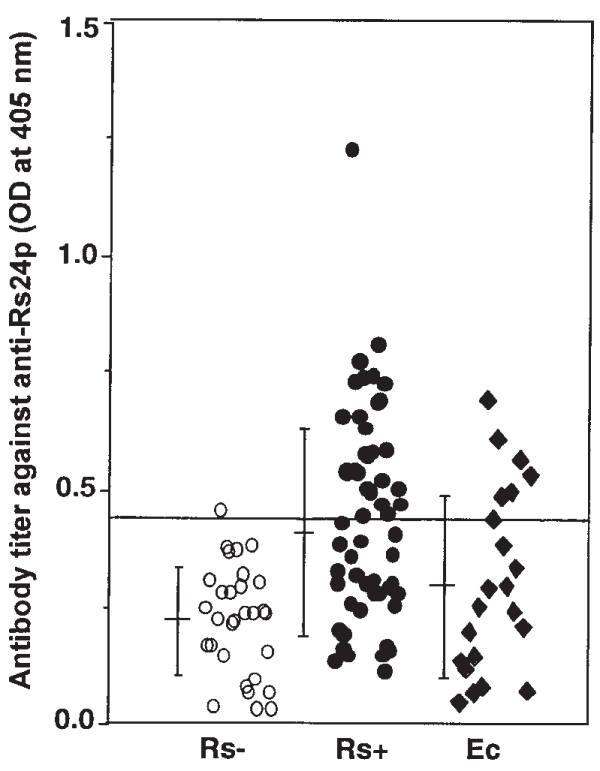

Figure 1. The titers of anti-Rs $24 p$ antibodies (OD at $405 \mathrm{~nm}$ ) in dogs from 3 groups: 30 ticknaive negative control dogs (Rs-: open circles), 57 positive control dogs naturally infested with ticks in Okinawa (Rs+: closed circle), and 22 E. canis antibody positive dogs (Ec: closed diamond). The bars represent the mean \pm standard deviation of the titers in groups Rs-, Rs+ and Ec. The horizontal line at 0.440 OD shows the cut off value.

\section{DISCUSSION}

In the present study, we evaluated the anti-Rs $24 p$ antibodies in canine sera using ELISA for epidemiological surveys on tick infestation. Larval tick extract was used as a source of antigen to detect antibodies with the ELISA, because the $24 \mathrm{kDa}$ protein derived from larvae can react with antibodies in dogs infected twice with adult ticks [5] and larvae can be treated more easily than saliva of adult ticks.

The mean titer in 3 dogs experimentally infested twice with adult $R$. sanguineus did not change until day 6 of the second infestation. The increased titer continued by day 24 of the second infestation. These findings suggested that anti-Rs $24 p$ was detected only during a short period after the second tick infestation. One of 3 experimental dogs showed lower titers even after the second infestation. Using a western blot technique in the previous study, the duration of antiRs $24 p$ after the second infestation also varied greatly among the animals [5]. Though there was a significant difference of mean titers between positive and negative controls, the titer of many individuals in the positive control showed a lower level compared with the cut off value calculated from the negative control (0.444). It has been proposed that the numbers, stage and repeated natural tick infestation affect the antibody titers in positive control dogs. Sanders et al. [9] reported that an increase in the number of Amblyomma americanum or Dermacentor variabilis ticks feeding on a rabbit, promoted the amount of rabbit anti tick-saliva $\mathrm{IgG}$ production. These experimental and natural findings suggest that detection of 
anti-Rs $24 \mathrm{p}$ antibodies could be used as a biological marker for repeated tick exposure however, a high risk of false negative results may occur in epidemiological studies because of limited sensitivity. The effect of repeated infestation, and the numbers or stage of ticks infested should be examined experimentally to evaluate the assay.

The mean \pm standard deviation of the titer in group Ec was $0.298 \pm 0.197$ and six dogs in group Ec showed titers higher than the cut off value (0.444), while the difference in the mean titer between groups Ec and Rswas not significant. The dogs that showed higher titers might have been concerned with the tick infestation, however, it is impossible to determine whether the repeated infestation with $R$. sanguineus really occurred because of the lack of information on tick infestation. Imported dogs from other countries [2] can introduce and establish $R$. sanguineus on the main land of Japan, and E. canis can also be simultaneously introduced [3]. Tick infestation should be examined in dogs that showed higher titers against Rs $24 \mathrm{p}$ in order to confirm the hypothesis. Recently E. muris was isolated from wild mice in Japan as a native ehrlichia. The antibody against $E$. muris can react with an antigen of $E$. canis, and the vector of E. muris may be Haemaphysalis spp. or Ixodes spp. [7]. This must be considered when explaining the lower titers of dogs that have antibodies against $E$. canis.

\section{REFERENCES}

[1] Groves M.G., Dennis G.L., Amyx H.L., Hursll, D.L., Transmission of Ehrlichia canis to dogs by ticks (Rhipicephalus sanguineus), Am. J. Vet. Res. 36 (1975) 937-940.

[2] Inokuma H., Tamura, K, Onishi T., Incidence of brown dog ticks, Rhipicephalus sanguineus, at a kennel in Okayama Prefecture, J. Vet. Med. Sci. 57 (1995) 567-568.
[3] Inokuma H., Yamamoto S., Morita C., Survey of tick-borne diseases in dogs infested with Rhipicephalus sanguineus at a kennel in Okayama Prefecture, Japan, J. Vet. Med. Sci. 60 (1998) 761563.

[4] Inokuma H., Yamamoto S. Tanahara N., Kiyuna T., Oshiro S., Surveys for tick infestation and tick-borne disease infection of dogs in Okinawaisland, J. Jpn. Vet. Med. Assoc. 51 (1998) 361364 (in Japanese with English summary).

[5] Inokuma H., Mukai M., Ohno K., Yamamoto Y., Takahashi S., Onishi T., Duration of antibodies against $24 \mathrm{kDa}$ protein of Rhipicephalus sanguineus extract in dogs infested with the adult ticks, J. Vet. Med. Sci. 61 (1999) 179-181.

[6] Inokuma H., Ohno K., Yamamoto S., Serosurvey of Ehrlichia canis and Hepatozoon canis infection in dogs in Yamaguchi Prefecture, Japan, J. Vet. Med. Sci. 61 (1999) 1153-1155.

[7] Kawahara M., Suto C., Rikihisa Y., Yamamoto S., Tsuboi, Y., Characterization of ehrlichial organisms isolated from a wild mouse, J. Clin. Microbiol. 31 (1993) 89-96.

[8] Rikihisa Y., Ewing S.A., Fox J.C., Siregar A.G., Pasatribu F.H., Malok M.B., Analyses of Ehrlichia canis and a canine granulocytic Ehrlichia infection, J. Clin. Microbiol. 30 (1992) 143-148.

[9] Sanders M.L., Glass G.E., Scott A.L., Schwartz B.S., Kinetics and cross-species comparisons of host antibody responses to lone star ticks and American dog ticks (Acari: Ixodidae). J. Med. Entomol. 35 (1998) 849-856.

[10] Schwartz B.S., Ribeiro J.M.C., Goldstein, M.D., Anti-tick antibodies: an epidemiologic tool in Lyme disease research, Am. J. Epidemiol.132 (1990) 58-66.

[11] Schwartz B.S., Ford D.P., Childs J.E., Rothman N, Thomas, R.T., Anti-tick saliva antibody: a biologic marker of tick exposure that is a risk factor for Lyme disease seropositivity, Am. J. Epidemiol. 134 (1991) 86-95.

[12] Schwartz B.S., Nadelman R.B., Fish D., Childs J.E., Forseter G., Wormser, G.P., Entomologic and demographic correlates of anti-tick saliva antibody in a prospective study of tick bite subjects in Westchester County, New York, Am. J. Trop. Med. Hyg. 48 (1993) 50-57.

[13] Yamaguchi N., Tipton V.J., Keegan H.L., Toshioka S., Ticks in Japan, Korea and Ryukyuislands, Brigham Young Univ.Sci. Bull. Biol. Ser. 15 (1971) 1-226.

[14] Yamamoto S., Honda M., Ashida Y., Nishimura Y., Niizeki H., Rikihisa Y., Detection of antibody to Ehrlichia canis in dogs, J. Jpn. Vet. Med. Assoc. 46 (1994) 395-397 (in Japanese with English summary). 